\title{
Dos procesos olvidados: la catástrofe demográfica y la imposición de «reducciones de indios" en el norte peruano
}

\author{
Guillermo Figueroa Luna \\ Universidad Nacional Pedro Ruiz Gallo, \\ <guillermofigueroaluna@yahoo.es>
}

Iris Liliana Vásquez Alburqueque

Universidad Nacional de Frontera, Sullana, Piura <ivasquez@unfs.edu.pe>

\section{RESUMEN}

Se constata que la apología de la fundación de ciudades para minorías, como supuesto inicio de la civilización a inicios de la Colonia (siglo XVI), sumada al silencio sobre la forzada imposición de pueblos de "indios" o reducciones, encubren la terrible catástrofe demográfica en la Costa Norperuana, causada por la aguda explotación y opresión de la mayoritaria población originaria, al lado de las nuevas enfermedades y el empobrecimiento de la dieta de los "indios". Además de sus efectos económicos y políticos esa apología y ese olvido contribuyen a una identidad que se identifica con los invasores y no con los pueblos originarios.

Palabras clave: Catástrofe demográfica; población originaria; pueblos de indios; colonia inicial.

\section{Two forgotten processes: the demographic catastrophe and the imposition of «reductions of Indians» in northern Peru}

\section{ABSTRACT}

It is verified that the apology for the foundation of cities for minorities, as the supposed beginning of civilization at the beginning of the Colony (16th century), added to the silence on the forced imposition of "Indian" towns or reductions, conceal the terrible demographic catastrophe in the North Peruvian Coast, caused by the acute exploitation and oppression of the majority native population, next to the new diseases and the impoverishment of the diet of the "Indians".

KeYwords: Demographic catastrophe; native population; Indian towns; initial colony. 


\section{Introducción}

A la población peruana, se le presenta generalmente la fundación de ciudades en el Perú colonial el siglo XVI como acción constructiva y hasta civilizatoria. Así, con la excepción del Cusco — que celebra como festividad central la fiesta andina del Inti Raymi- las ciudades de Piura, Chachapoyas, Lima, Trujillo, Huamanga, Arequipa, Huánuco y otras, todas fundadas por los conquistadores hispanos, no solo celebran el día de esa fundación como su festividad central, sino que también ostentan hasta hoy el escudo otorgado por el monarca espańol como emblema de la ciudad.

Esto es así, porque el dominio colonial tiene como uno de sus componentes la "conquista de las almas", es decir, la transculturación forzada, que - al mismo tiempo de enaltecer la cultura metropolitanaimpone el menosprecio por la historia y los valores de los países y poblaciones invadidos. El poder construye entonces una nueva identidad de conquista y "gobierno y policía", a la cual busca asimilar —en una posición subordinada - a la población sojuzgada.

Como señala la historiadora Susan Ramírez, la población andina originaria sintió estos cambios como "un mundo al revés" (2002: 18). Pero, sin prestar atención a los pobladores originarios, "Los investigadores [...] se ocupaban de las instituciones importadas y su función, así como de la vida de las elites. [...] De este modo, la historia del colonialismo en América estaba esencialmente desequilibrada". (Ramírez 2002: 14).

Desequilibrio que revela la extendida concepción sobre los invasores europeos como protagonistas de la historia, considerando a los pobladores nativos como bárbaros o salvajes que vivían en total desorden o "behetría". En la costa norperuana, este desequilibrio se revela agudamente, por ejemplo, en la exaltación que el Congreso de la República, el Instituto Nacional de Cultura y el Municipio Provincial de Piura hacen de esta ciudad "la primera ciudad fundada por los españoles en el Pacífico Sur” (Moya 2003 y 2009; Correa 2018, Seminario 1986), título que les disputa con razón — en cuanto a la cronología - la Villa de Tangarará de la provincia de Sullana.

En los casos de Lambayeque y Chiclayo —antigua y actual capitales de la región lambayecana, respectivamente-, ambas exaltan su supuesta "fundación española como ciudad", aunque ningún historiador ha señalado siquiera la fecha de ese hecho. (Zevallos 1995: 23), porque nunca fueron fundadas como tales. Fueron organizadas, impuestas, como "reducciones" o "pueblos de indios", es decir, organismos proveedores de mano de obra entre barata y gratuita, así como de dinero y bienes bajo los regímenes de la mita y el tributo. Eran económica y políticamente importantes, pero de baja categoría en la ideología colonial.

Y, paralelamente a la supuesta benevolencia asignadas a esas reales o imaginarias fundaciones, las instituciones, personas y comunicadores que se explayan sobre ellas, omiten casi absolutamente - ya sea por falta de información o porque no le dan importancia- referirse a los efectos de la opresión colonial sobre la salud y la cantidad de población originaria, que —en la Colonial Inicial— era abrumadoramente mayoritaria en todas las regiones. Para demostrar este grave desinterés y falta de identificación del Estado y de la historia oficial con la población originaria, vamos a examinar dos importantísimos procesos que suceden a dichas fundaciones y que son consecuencia directa de la invasión hispana y de los cambios políticos, económicos y biológicos impuestos: la enorme disminución de la población originaria y la organización compulsiva de reducciones o "pueblos de indios", entre 1532 y 1602, período al que consideramos como la Colonia Inicial

Entendiendo por identidad "el sentimiento de pertenencia a un grupo social" (Vilar 1982), el objetivo del presente trabajo es comprender como grave la omisión de la catástrofe demográfica y la exaltación de la fundación de ciudades en la Colonia Inicial en la costa norte tienen como resultado una imagen muy tergiversada de ese período, asociada a una identidad que no ha deslindado con el colonialismo.

\section{Material y métodos}

Los procesos a examinar son:

1) El proceso del drástico descenso de la población nativa entre la conquista e inicios del siglo XVII. Se examinará la estadística elaborada por los funcionarios españoles sobre las poblaciones originarias, 
desde el primer año registrado en cada lugar (entre 1532 y 1570), hasta 1602, año cuyos registros son bastante completos; y que marca grosso modo el fin de lo que llamamos Colonia Inicial.

Dada la irregularidad y escasez de registros coloniales sobre las mujeres y los menores, nos centraremos en la población tributaria, es decir, varones mayores de 18 años, sobre quienes la información es más completa. La unidad territorial se refiere mayormente a los "repartimientos" coloniales, tomando en cuenta que sus variaciones han sido compensadas en lo posible por los especialistas que citamos, los que han procesado con cuidado las cifras demográficas de las "visitas" y censos coloniales.

2) La terrible desestructuración que en la organización económica, política y cultural originaria, por efecto de la política colonial de agrupar forzadamente a la población originaria en "reducciones" o "pueblos de indios", con el objetivo de tenerla absolutamente controlada, evitando la elusión del trabajo forzado de la mita y el pago de tributos, principales formas de la explotación colonial.

Aunque estas "reducciones de indios" fueron establecidas en todo el Virreinato peruano y no obstante que —en la nueva historiografía - son bastante conocidos los visitadores y sus informes, este proceso nunca o rara vez es mencionado en los libros regionales, ni en los textos para la educación primaria y secundaria, como origen de la gran mayoría de pueblos antiguos del Perú. Menos aún, por los medios de comunicación, las agencias de turismo, los centros educativos y los organismos estatales encargados de la educación y de la cultura.

Nuestras hipótesis son:

1) La versión histórica del Estado, medios de comunicación y la mayoría de quienes han escrito sobre el período, al omitir la mención y el estudio de la catástrofe demográfica andina, impiden la comprensión del sistema colonial y revela el poco interés por comprender la vida de los habitantes originarios, tomando a los colonizadores como únicos o principales protagonistas de la historia, lo que no ha cambiado con los actuales discursos de admiración por las culturas originarias.

2) Del mismo modo, el desconocimiento o incomprensión de los graves efectos de las reducciones o "pueblos de indios" y de la catástrofe demográfica del siglo XVI, al ocultar y embellecer la cruel política colonial, abonan a la construcción y vigencia de identidades conciliadas con el colonialismo.

\section{Resultados y discusión}

\section{1) La Catástrofe Demográfica en Tumbes. Piura y Lambayeque}

TABla 1. Población originaria* de la costa de Piura y Tumbes

Tributarios (varones adultos) 1532-1602

\begin{tabular}{|c|c|c|c|c|c|}
\hline \multirow{2}{*}{ Lugar } & \multicolumn{2}{|c|}{ Año del censo } & \multicolumn{2}{|c|}{$\mathrm{N}^{\circ}$ de tributarios } & \multirow{2}{*}{$\begin{array}{c}\% \\
\text { Variación }\end{array}$} \\
\hline & Año base & Último año & Año base & Último año & \\
\hline Tumbes & 1549 & 1602 & 400 & 12 & -97 \\
\hline Máncora & 1573 & 1602 & 20 & 4 & -80 \\
\hline Amotape & 1573 & 1602 & 34 & 9 & -74 \\
\hline Colán & 1573 & 1602 & 163 & 30 & -82 \\
\hline Paita y Lisilla & 1532 & 1602 & 300 & 27 & -91 \\
\hline Marcavelica & 1549 & 1602 & 100 & 16 & -84 \\
\hline Solana & 1573 & 1602 & 217 & 60 & -72 \\
\hline Tangarará & 1573 & 1602 & 25 & 9 & -64 \\
\hline
\end{tabular}

* Preferimos este término porque el de "indígenas" -utilizado por muchos organismos internacionales y estatales- es comprendido por la mayor parte del público con la misma carga discriminatoria que el de "indios".

Fuente: Elaboración nuestra en base a Noble David Cook, La Catástrofe Demográfica Andina. Perú 1520-1620 
Gráfico 1. Disminución de la población originaria de Tumbes y Piura 1532-1602

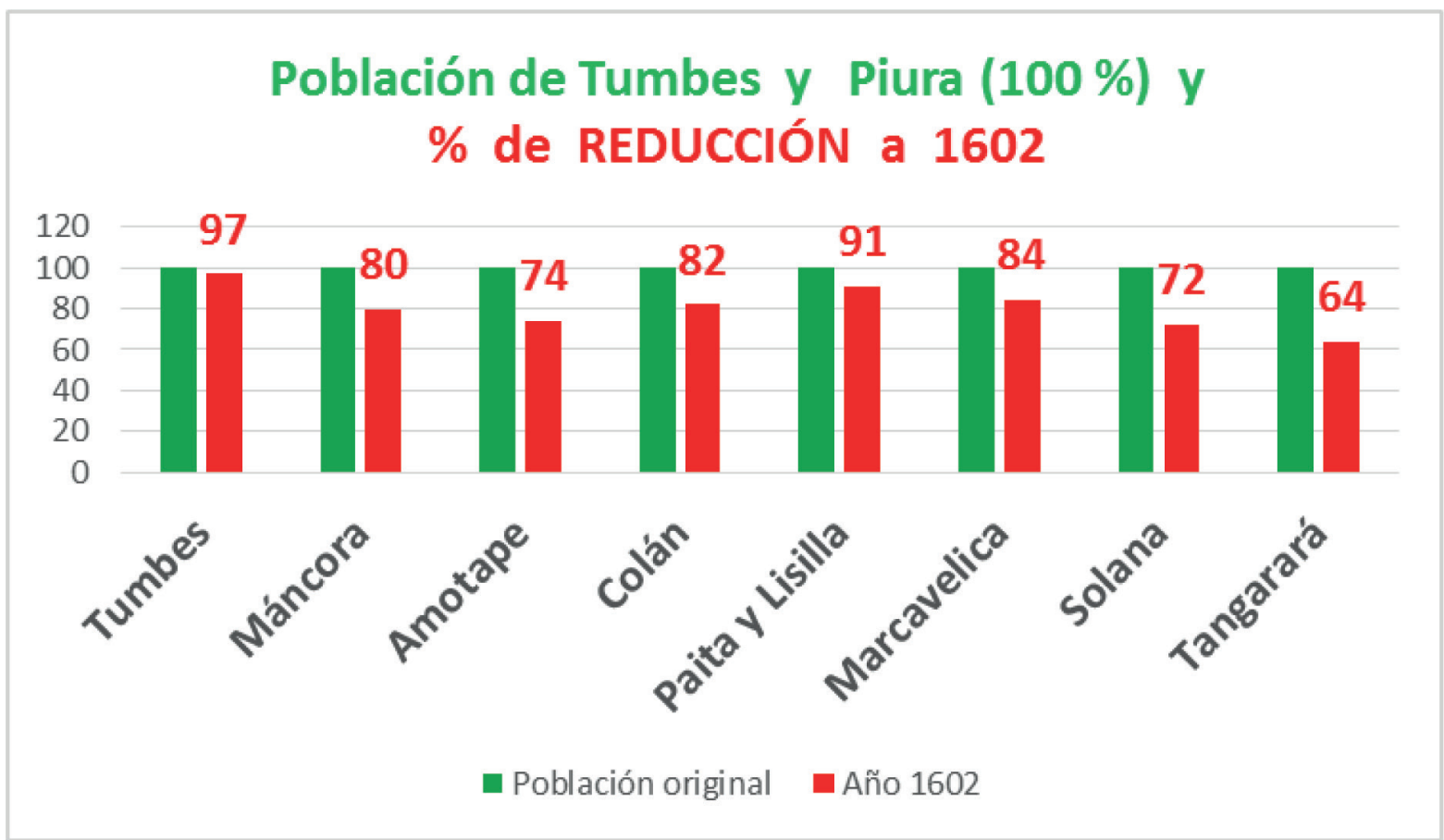

Gráfico 2. Disminución de la población originaria de la sierra de Piura.

Tributarios 1573-1602 (en \%)

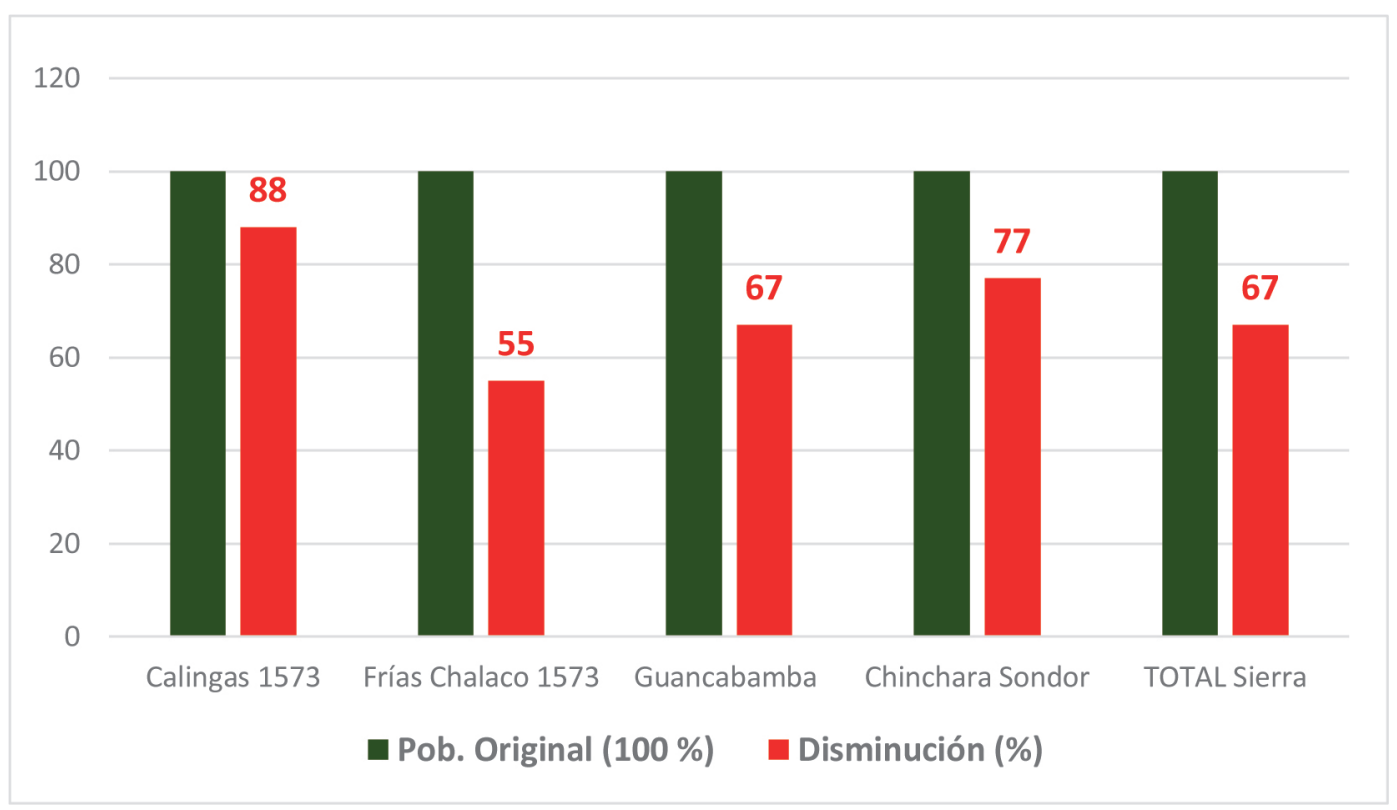

En lo que respecta a la población total (varones y abundante, pero muestra la misma tendencia que la mujeres de todas las edades), la información es menos población tributaria. 
Tabla 2. Población tributaria de Lambayeque 1549-1602

\begin{tabular}{|c|c|c|c|c|}
\hline \multirow{2}{*}{ Repartimiento } & \multicolumn{2}{|c|}{$\mathrm{N}^{\circ}$ de tributarios } & \multicolumn{2}{|c|}{ Disminución } \\
\hline & $1549-1575$ & 1602 & $\mathrm{~N}^{\circ}$ & $\%$ \\
\hline Copiz & 200 & 13 & 187 & 93.5 \\
\hline Olmos & 382 & 305 & 77 & 20.2 \\
\hline Motupe & 543 & 248 & 295 & 54.3 \\
\hline Penachí & 500 & 160 & 340 & 68.0 \\
\hline Jayanca & 1248 & 355 & 893 & 71.6 \\
\hline Pacora & 234 & 78 & 156 & 66.7 \\
\hline Illimo & 834 & 279 & 555 & 66.5 \\
\hline Túcume & 1554 & 613 & 941 & 60.6 \\
\hline Ferreñafe & 535 & 224 & 311 & 58.1 \\
\hline Lambayeque & 1584 & 1065 & 519 & 32.8 \\
\hline Zaña & 320 & 141 & 179 & 55.8 \\
\hline Cinto y Chiclayo & 731 & 349 & 382 & 52.3 \\
\hline TOTAL & 8665 & 3830 & 4835 & 55.8 \\
\hline
\end{tabular}

Fuente: Noble David Cook 2010, op. cit. Elaboración nuestra.

Gráfico 3. Reducción de la población tributaria Lambayeque 1549-1602 (en \%)

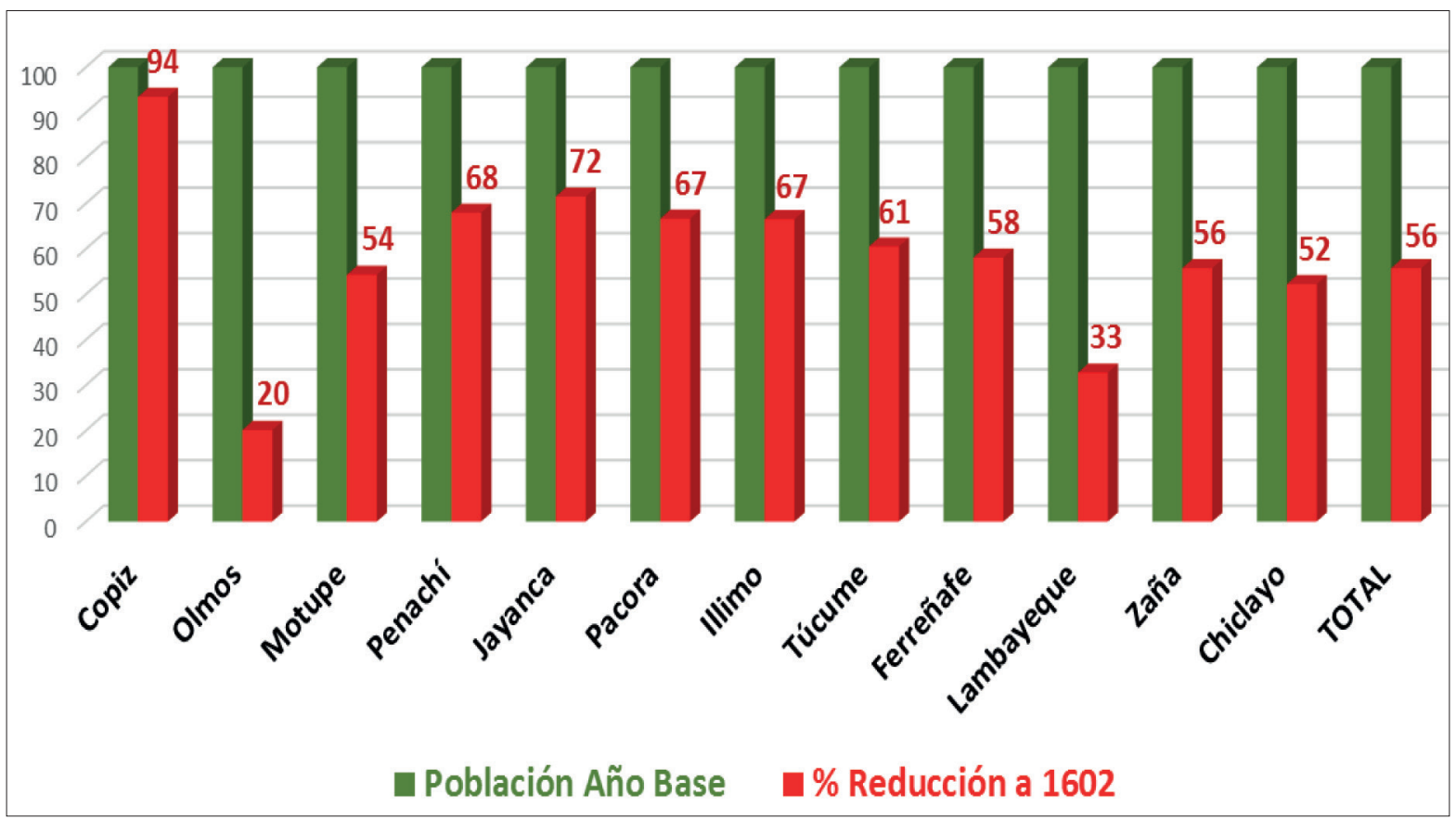

Fuente: Cook, op. cit. Elaboración nuestra.

Otra síntesis reciente señala: "Para el caso de Piura, en el siglo XVI, el número de tributarios cayó de poco más de 20,000 a menos de 6,000; y disminuyó la población total de 77,000 a 23,000 aproxi- madamente" (Gutiérrez, 2017: 320). Una visión que amplía el espacio norteńo nos la proporciona la historiadora Susan Ramírez. 
TABla 3. Habitantes y tributarios de Piura y Lambayeque 1532-1625

\begin{tabular}{|l|c|c|c|c|c|}
\hline \multicolumn{1}{|c|}{ Repartimiento } & Año & Tipo & N $^{\circ}$ & Año & N $^{\circ}$ \\
\hline Colán & 1569 & Habitantes & 1,225 & 1583 & 965 \\
\hline La Chira & 1573 & Tributarios & 61 & 1625 & 17 \\
\hline Piura & 1548 & Tributarios & 14,250 & 1561 & 6,054 \\
\hline Zańa & 1532 & Tributarios & 3,000 & 1591 & 219 \\
\hline
\end{tabular}

Fuente. Susan Ramírez 2017, p. 85. Elaboración nuestra.

Gráfico 4. Población de 2 zonas del norte 1540-1606

Total y disminución (en \%)

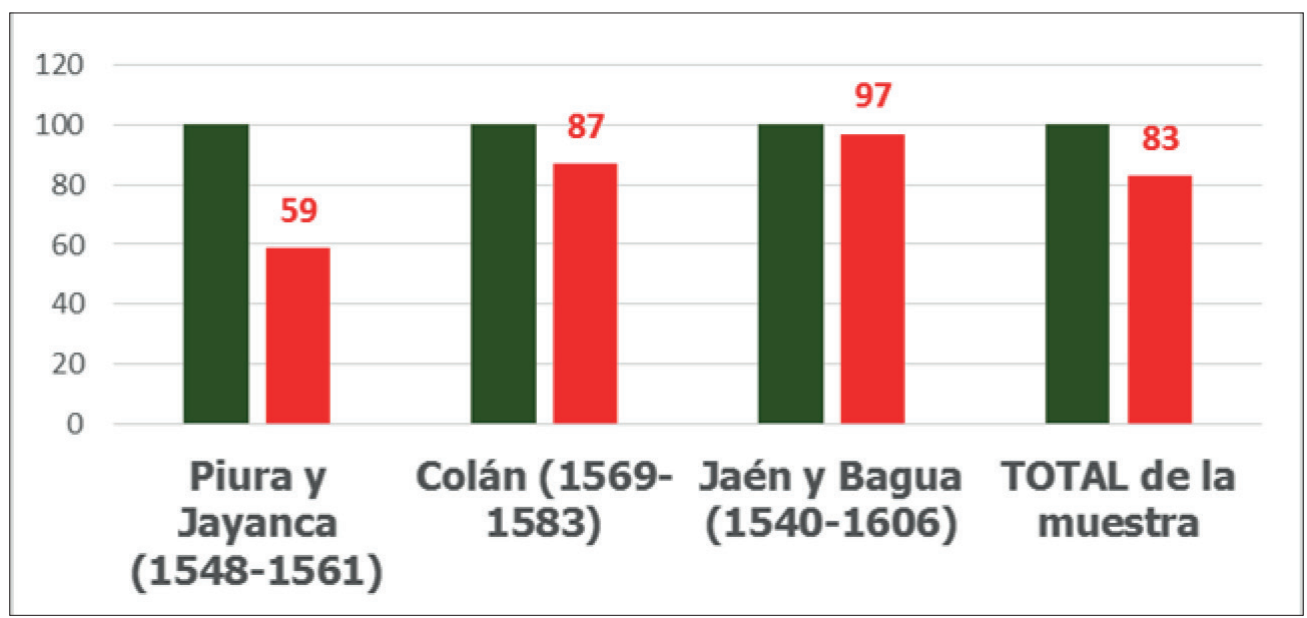

Fuente: Elaboración nuestra en base a Ramírez 2017 "Historia económica del norte peruano”, p. 85.

En cuanto a las causas de esta evolución demográfica, el historiador Carlos Sempat Assadourian, luego de establecer "dos hechos fundamentales: la alta densidad de población alcanzada por estas sociedades agrícolas y su catastrófica reducción a consecuencia de la invasión europea", propone como la causa de este fenómeno: "Las guerras de conquista y entre las mismas huestes españolas" (Sempat, 1989: 420).

Por su parte, la historiadora Susan Ramírez señala con claridad que "la drástica despoblación de los pueblos originarios [...] resultó del trabajo excesivo, como caminar largas distancias llevando mucha carga pesada, otros abusos, las guerras civiles y las epidemias de sarampión, viruela y el mal de bubas" (2017: 84).

Asimismo, dicha autora ha documentado que "El encomendero exigía, sin tener en cuenta el descenso de población [...]. Al reducirse la población nativa, los supervivientes se veían obligados a trabajar más. Los indios que no lograban cubrir las cuotas de producción marcadas recibían brutales castigos" (Ramírez 1991: 50).

\section{2) La Reducción de Indios como reorganización compulsiva de pueblos}

Las autoridades coloniales del siglo XVI solo crearon ocho ciudades (Piura, Jauja, Lima, Trujillo, Huamanga, Arequipa, Chachapoyas y Huánuco), todas ellas con las funciones de 1) guarnición militar, 2) centro de comercio y de acopio de las riquezas saqueadas o excedentes creados, 3) centro de organización del adoctrinamiento compulsivo de la población originaria; y 4) lugar de vivienda de los encomenderos, comerciantes, hacendados y otros miembros de la clase dominante colonial.

Como sostiene Susana Aldana (2002: 75-83), las ciudades tuvieron una función decisiva en el control político del territorio y de la sociedad. Constituyeron claramente un espacio para los "españoles", a quienes se repartía lotes o "solares" de terreno urbano, mientras los "indios" no los recibían. En Tangarará, unos 40 a 45 invasores recibieron tales solares, de igual modo que en Trujillo, Lima, etc. 
A diferencia de ellas, el patrón de vivienda originario era disperso, con agrupamientos que rara vez superaban las diez viviendas. Esto se aprecia - entre otras- en la Visita de Jayanca, realizada por el corregidor de Piura Sebastián de la Gama en 1540 (Espinoza, 1975: 250-270).

Este patrón disperso era racional en el sistema económico andino, que se basaba en la reciprocidad y la redistribución, con un alto nivel de legitimidad de los jefes étnicos. Esto originaba que las prestaciones de los pobladores - que nunca fueron en especie sino solo en trabajo (Ramírez, 2002: 53-59)—- tenían tanta aceptación que la dispersión de las viviendas no constituía problema.

Pero, como la Colonia destruyó esa legitimidad e impuso un sistema económico basado en un alto grado de coacción, la dispersión de las viviendas fue aprovechada por los pobladores originarios para elu- dir — cuando podían hacerlo- el trabajo obligatorio (mita) y el pago del tributo.

Por eso, el Estado colonial dispuso una de las políticas más crueles y destructivas de toda la historia universal: bajo la amenaza de quemar sus casas, obligaron a los pobladores a trasladarse a vivir en los lugares que se les designó, es decir a las "reducciones de indios".

Así, como paso decisivo en la destrucción de la cultura original, se establecieron las «reducciones» o "pueblos de indios» (ver tabla 4). Varios de ellos como Catacaos, Sechura, Ayabaca, Monsefú o Chiclayo son ahora capitales de distritos o provincias. Sus características principales fueron:

1) Los "indios" solo podían salir a cultivar sus chacras de 6 de la mañana a 6 de la tarde, so pena de perder su tierra y quedar para siempre como "indios forasteros".

TABla 4. Reducciones de indios de Tumbes, Piura y Lambayeque 1567-1575

\begin{tabular}{|c|c|c|}
\hline & Pueblos o parcialidades originarias & Reducciones \\
\hline \multirow{10}{*}{ 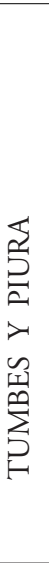 } & Tumbes Máncora, Solana y unos indios de Amotape & San Nicolás de Tumbes \\
\hline & Colán, Malacas. Camacho, Guaura, Nizama y Vitonera & San Lucas de Colán \\
\hline & Paita, Castillo y La Silla & San Francisco de la Buena Esperanza de Paita \\
\hline & $\begin{array}{l}\text { La Chira, Poechos, Pariñas, Cusio, Mechato, Mecomo, Amotape, } \\
\text { Marcavelica, Mecache, Menón, Tangarará, Narigualá, Melén y Zibar }\end{array}$ & San Juan del Valle de Catacaos \\
\hline & Sechura, Nunura, Pisura, Punta, Aguja y Muñuela & San Martín de Sechura \\
\hline & Olmos Santovelico, Partizeros, Guambra, Julisana, Catón y Niero & Santo Domingo de Olmos \\
\hline & Frías, Chalaco y Chinchacara & San Andrés de Frías \\
\hline & Ayabaca, Chocán y Collanas & N.S. del Pilar de Ayabaca \\
\hline & Copiz & San Francisco de Copiz \\
\hline & Huancabamba, Huarmaca. & San Pedro de Huancabamba \\
\hline \multirow{11}{*}{ 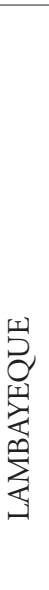 } & Pueblo de Pescadores y Callanca & Callanca \\
\hline & Chérrepe, Choloc, Noquique e indios viejos del Tambo Real & Chérrepe (nuevo asiento) \\
\hline & Collique, Sinto y 300 tributarios de Pololo & Chiclayo \\
\hline & Callanca & Monsefú \\
\hline & 100 indios del Camino Real a Saña & Moro \\
\hline & Sinto & Picsi \\
\hline & Moclla & Pololo \\
\hline & Mitimaes de Saña & Tres pueblos \\
\hline & Mayna & Reque \\
\hline & Repartimiento de San Salvador de Jayanca & Tres pueblos \\
\hline & Tecaza & San Pedro de Lloc \\
\hline
\end{tabular}

Fuente: Diez, 2004: 13; y Ramírez, 2002: 69. Resumen nuestro. 
2) El pago del tributo y la asistencia a la mita, a misa $\mathrm{y}$ adoctrinamiento quedaron bajo el estrecho control del corregidor y sus tenientes, los alguaciles, los kurakas, mandones y sacerdotes.

3) Se estableció en cada reducción un "Cabildo de Indios", con atribuciones muy limitadas, pues se ocupaba de asuntos solo hasta por 5 pesos y su "procurador (protector) de naturales" lo era solo de nombre. Solamente las ciudades de Piura la Vieja y Chiclayo; y la Villa de Saña tuvieron Cabildo de Españoles, del que los "indios" estuvieron excluidos.

4) El trazo del pueblo era cuadriculado, en torno a una plaza principal, donde se ubicaban el templo, el local del cabildo y la casa del sacerdote, únicos edificios de adobe.

5) Las viviendas de los "indios" se construían sobre lotes de 10 por 20 varas $(8 \times 16 \mathrm{~m}$, aproximadamente) y eran de quincha. Solo el kuraka o cacique podía tenerla de adobe (ver Cruz 1984).

6) En la plaza central de cada reducción se estableció obligatoriamente una horca y una "picota", es decir, un poste especial para colgar y azotar a los "indios" que cometían alguna falta como no asistir a misa. En la parte trasera del local del Cabildo se construía una cárcel, de gruesas paredes y rejas de hierro.

Es decir, el sistema ejercía una violencia "cara a cara" (Flores-Galindo 1984: 146).

Los visitadores nombrados por el virrey para organizar las reducciones en el norte fueron Bernardino Loayza para Piura, y Gregorio Gonzales de Cuenca, al que sucedió Juan de las Hoces, para Lambayeque. (Espinoza 2004).

No fueron medidas aisladas ni regionales, pues en todo el Virreinato peruano, en las décadas de $1560 \mathrm{y}$ 1570 , se encerró a las poblaciones originarias en las reducciones. "En los inicios del gobierno del virrey Francisco de Toledo, entre 1570 y 1575, se crearon alrededor de mil reducciones para una población de un millón y medio de habitantes" (Saito y Rosas 2017). Todo el país quedó convertido en un enorme campo de concentración, bajo el control de los corregidores, los "cabildos de indios", los sacerdotes y los alguaciles.

En base a su investigación de más de 30 años sobre la región, Susan Ramírez resume los efectos políticos y económicos de ese proceso:
La despoblación dejó a los campesinos más diseminados que antes. Así, se dispuso que se concentraran en pueblos nuevos, llamados reducciones, lo que hacía más fácil su control. La congregación de la población dispersa simplificó las tareas de evangelización, la recolección de tributos y la organización de la mano de obra... La reducción de estos habitantes y la reasignación de tierras y aguas de regadío dejaron las tierras más fértiles abiertas para el uso de los españoles y, con la prohibición colonial de viajar, fijaron a la población nativa en un sitio. (Ramírez 2017: 85)

Las "reducciones" causaron enormes sufrimientos y mucha mortandad. El arqueólogo Haagen (2010) ha documentado lo que llama "estress biológico", causado por el cambio de alimentación, que pasó de una dieta balanceada a otra de casi solo maíz en la Colonia Inicial (ver Gráfico 3).

GrÁfico 3. El deterioro de la salud en las reducciones: Restos humanos en Eten y Mórrope

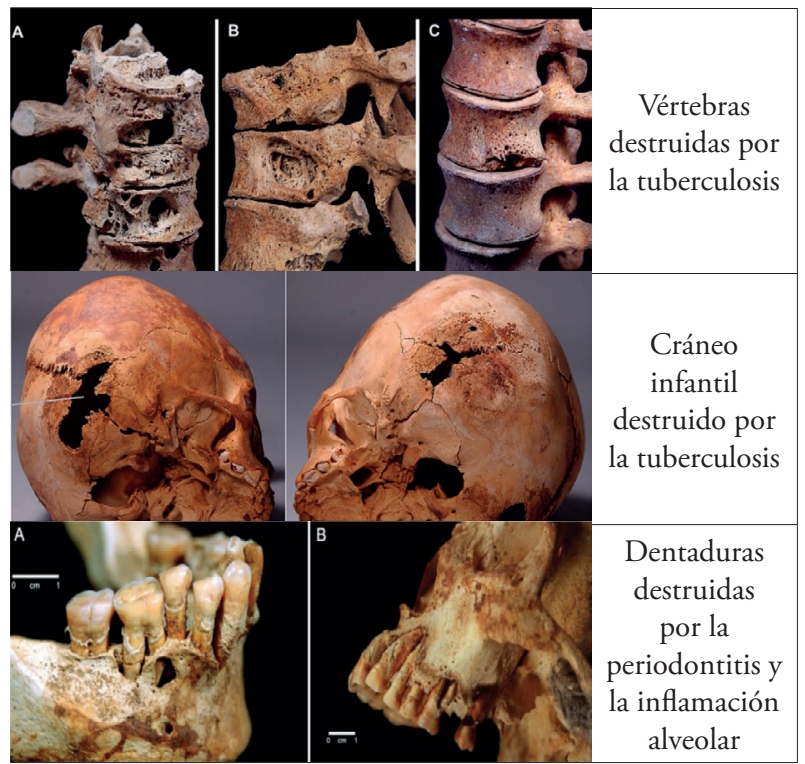

Fuente: Haagen 2010. Subtítulos nuestros.

Sus excavaciones en el interior y alrededor de las Iglesias de Mórrope y Eten muestran no solo el incremento de la mortalidad, sino también un terrible deterioro de las articulaciones, cráneo y dentadura de nuestros antepasados en las citadas reducciones. 


\section{Conclusiones}

Los terribles procesos de morbi-mortalidad y drásticos cambios económicos y políticos reseñados tuvieron sin duda efectos también terribles no solo sobre la vida material de las etnias o pueblos originarios de la región norperuana Tumpis, Tallanes, Lambayeques, Guayacundos y Bracamoros ${ }^{1}$, sino también sobre la identidad de tales pueblos y de la población norteńa actual.

La situación actual de olvido, ocultamiento o minimización de los sufrimientos de nuestros antepasados - y de su resistencia al colonialismo- muestra que en la identidad norteńa actual hay graves vacíos y tergiversaciones, no solo por el escaso acceso de las instituciones y la población al conocimiento historiográfico, sino principalmente por el predominio de la versión apologética del dominio colonial, mecanismo ideológico y político del colonialismo o de la colonialidad del poder (ver Aníbal Quijano 2014: 44).

En tal situación, para la construcción y desarrollo de la identidad nacional en construcción, y las identidades regionales, las universidades, centros educativos y organizaciones representativas en general deben fortalecer su labor de investigación historiográfica y de extensión cultural, así como desarrollar un intenso debate en torno a los nuevos aportes historiográficos, que no pueden limitarse a los ámbitos académicos e intelectuales.

Asimismo, es necesario superar la actual formación de los docentes como repetidores de textos, impulsando su espíritu crítico e investigativo; y dotándoles de capacidades metodológicas histórico-lógicas, analítico-sintéticas, eurísticas y hermenéuticas, para hacer del conocimiento de la historia de nuestros pueblos una fuerza espiritual hacia la transformación social.

1 Sobre estas etnias norteńas, ver: Espinoza-Claudio 1999, EspinozaSoriano 2016 (Tumpis); Huertas 2001 y Hocquenghem 1991 (Tallanes); Wester y Fernández 2014 y Narváez 2014 (Lambayeques); Hocquenghem 1990 y Espinoza-S. 2004A (Guayacundos); Espinoza-S. 1994 y Martín-C. 1990 (Bracamoros).

\section{Referencias bibliográficas}

Aldana, Susana (2002). "La ciudad en las Indias peruanas, un instrumento de control político". En Cuadernos de Historia $\mathrm{N}^{\circ} 1$. Trujillo.

Соок, Noble David (2010). La catástrofe demográfica andina. Perú 1520-1602. Lima: Pontificia Universidad Católica del Perú.

Correa, Yanina (2018). "San Miguel de Piura recupera la fecha más acorde para celebrar su fundación". (Entrevista). Piura. Arzobispado de Piura. http://arzobispadodepiura.org/ noticias/locales/san-miguel-de-piura-recuperala-fecha-mas-acorde-para-celebrar-su-fundacion/

Cruz-V, Jacobo (1982). Cataccaos. Origen y evolución histórica de Catacaos. Piura: Centro de Investigación y Promoción del Campesinado.

Diez, Alejandro (2006). "Los problemas del poder: Política local y gobierno en las reducciones de la costa de Piura, siglo XVII". Antrhopologica N ${ }^{\circ}$ 24. 107127. Lima: Pontificia Universidad Católica del Perú.

Diez, Alejandro (2010). Propiedad y territorio como (diferentes) bienes comunes. El caso de las tierras de comunidades en la costa norte peruana. http://dx.doi. org/10.17141/ eutopia.11.2017.2851.

Espinoza Claudio, César (1999). Sociedad indígena, tierra y curacazgos yungas en la región de Piura, siglos XVI-XVIII. Catacaos y los desafíos de la naturaleza, 1532-1732. Tesis de maestría PUCP, Lima.

Espinoza, Waldemar (1975). «El valle de Jayanca y el reino de los mochica. Siglos XV y XVI». En: Boletin del Instituto Francés de Estudios Andinos. Lima, Tomo IV, No 3-4, pp. 243-274.

Espinoza, Waldemar (1994). Historia de la peruanidad de Jaén de Bracamoros. Lima, Banco Central de Reserva del Perú.

EsPinOZA, Waldemar (2004). "El reordenamiento de las reducciones y comunidades de Lambayeque a Trujillo. Siglo XVI. Las Ordenanzas de Juan de Hoces, 1574". Uku Pacha Revista de Investigaciones Históricas $\mathrm{N}^{\circ}$ 7-8, Lima, OEI. https://www.oei.es/historico/n12117.htm

Espinoza, Waldemar (2004A). "La etnia Guayacundo en la sierra piurana”. Lima, Boletín de Arqueología PUCP, $\mathrm{N}^{\circ} 8$.

Espinoza, Waldemar (2016). "Etnia Tumpi (hoy Tumbes)". Investigaciones Sociales $\mathrm{N}^{\circ}$ 36. Lima, Universidad Nacional Mayor de San Marcos. http://revistasinvestigacion.unmsm.edu.pe/index.php/sociales/article/ view/12905/11594 
Flores, Alberto (1984). Aristocracia y plebe. Lima, 17601830. Estructura de clases y sociedad colonial. Lima: Ed. Mosca Azul.

Gutiérrez, Julissa (2017). "Esclavitud y mano de obra en el norte del Virreinato peruano". Historia económica del norte peruano. 315-353. Lima: Banco Central de Reserva del Perú e Instituto de Estudios Peruanos.

HaAgen, Klaus (2010). Vida y muerte en el Perú colonial: la bioarqueología de Lambayeque histórico. Behavioral Science Department, Utah Valley University; y Museo Sicán, Lambayeque, Perú.

Hocquenghem, Anne Marie (1990). Los Guayacundos de Caxas y la sierra piurana. Lima: Instituto Francés de Estudios Andinos.

Hocquenghem, Anne Marie (1991). "Fronteras entre 'Áreas culturales' nor y centroandinas en los valles de la costa del extremo norte y peruano". Boletín del Instituto Francés de Estudios Andinos Vol. 20.2. Lima: IFEA.

Huertas, Lorenzo (2001). Diluvios andinos a través de las fuentes documentales. Lima: Fondo Editorial de la PUCP.

Martín, José (1990). Jaén de Bracamoros Siglo XVI, Tomo II. Lima: Librería Studium.

Moya, Reynaldo (2003). Reseña histórica de Piura. Ed. Caja Municipal de Piura. http: //laperladelchira01.blogspot. $\mathrm{com} /$

Moya, Reynaldo (2009). Historia de Sullana. http ://reymoes.blogspot.com/2009/06/capitulo-I-resena-historica-de-sullana.html.

Narváez, Alfredo (2014). Dioses de Lambayeque. Chiclayo: Ministerio de Cultura Proyecto Especial Naylamp.

Quijano, Aníbal (2014). "Colonialidad del poder, eurocentrismo y América Latina”. En: Cuestiones y horizontes: de la dependencia histórico-estructural a la colonialidad /descolonialidad del poder. Buenos Aires: CLACSO, 2014.
Ramírez, Susan (1991). Patriarcas provinciales. La tenencia de la tierra y la economía del poder en el Perú colonial. Madrid: Alianza Editorial.

Ramírez, Susan (2002). El mundo al revés. Contactos y conflictos transculturales en el Perú del siglo XVI. Lima: Fondo Editorial de la Pontificia Universidad Católica del Perú.

Ramírez, Susan (2017). "La economía colonial del norte peruano". Historia económica del norte peruano. Señorios, haciendas y minas en el espacio regional. Lima: Banco Central de Reserva del Perú e Instituto de Estudios Peruanos.

Sarto, Akira y Rosas, Claudia. Reducciones. La concentración forzada de las poblaciones indígenas en el Virreinato del Perú. Lima: Fondo Editorial Pontificia Universidad Católica del Perú / Osaka, National Museum of Ethnology.

Seminario, Arturo (1986). Historia de Sullana. Sullana, Ed. Concejo Municipal de Sullana e Instituto provincial de Cultura. https://www.google.com.mx/ search?q=Seminario\%2C+ ArturoHistoria + de+Sullana \&rlz=1C1CHBD_esPE770PE770\&oq=Seminario\%2 $\mathrm{C}+$ Arturo+Historia+de+Sullana\&aqs=chrome..69i57. 14346j1j7\&sourceid=chrome\&ie=UTF-8

Sempat, Carlos (1989). "La despoblación indígena en Perú y Nueva Espańa durante el siglo XVI y la formación de la economía colonial". Historia mexicana. V. 38.3:419-453. México D.F. Ehttps: //www.jstor.org/ stable/25138230.

Wester, Carlos y Fernández, Julio (2014). Cultura Lambayeque en el contexto de la costa norte del Perú. Chiclayo, Ed. EMDECOSEGE.

Zevallos, Jorge (1995). Historia de Chiclayo. Siglos XVI, XVII, XVII y XIX. Lima: Ed. Minerva. 